\title{
Sensitivity of the thermohaline circulation in coupled oceanic GCM - atmospheric EBM experiments
}

\author{
Gerrit Lohmann"1, Rüdiger Gerdes $^{1}$, Deliang Chen ${ }^{2}$ \\ ${ }^{1}$ Alfred-Wegener-Institut, Am Handelshafen 12, D-27570 Bremerhaven, Germany \\ ${ }^{2}$ Laboratory of Climatology, Physical Geography, Earth Sciences Centre, Göteborgs University, Sweden
}

Received: 12 September 1994 / Accepted: 6 November 1995

\begin{abstract}
We analyze the sensitivity of the oceanic thermohaline circulation (THC) regarding perturbations in fresh water flux for a range of coupled oceanic general circulation - atmospheric energy balance models. The energy balance model (EBM) predicts surface air temperature and fresh water flux and contains the feedbacks due to meridional transports of sensible and latent heat. In the coupled system we examine a negative perturbation in run-off into the southern ocean and analyze the role of changed atmospheric heat transports and fresh water flux. With mixed boundary conditions (fixed air temperature and fixed surface fresh water fluxes) the response is characterized by a completely different oceanic heat transport than in the reference case. On the other hand, the surface heat flux remains roughly constant when the air temperature can adjust in a model where no anomalous atmospheric transports are allowed. This gives an artificially stable system with nearly unchanged oceanic heat transport. However, if meridional heat transports in the atmosphere are included, the sensitivity of the system lies between the two extreme cases. We find that changes in fresh water flux are unimportant for the THC in the coupled system.
\end{abstract}

\section{Introduction}

Modelling oceanic variability associated with the thermohaline forcing requires surface boundary conditions that allow anomalies to develop and persist for some time. While air-sea heat fluxes damp SST anomalies quite effectively, surface salinity anomalies can last for long periods.

The commonly used restoring boundary conditions for surface temperature $T$ (Haney 1971) and surface salinity $S$,

Correspondence to: R. Gerdes
$Q=c_{p} \rho_{0} \Delta z_{1} \gamma^{T}\left(T-T^{*}\right)$

$H F=\Delta z_{1} \gamma^{S} \frac{\left(S-S^{*}\right)}{S_{0}}$

with typical e-folding times $1 / \gamma^{T}, 1 / \gamma^{S} \approx 1$ month for the adjustment of the uppermost model level (at the centre of the uppermost grid box of thickness $\Delta z_{1}$ ) excessively damp variability by constraining the surface values to lie close to prescribed temperatures and salinities $T^{*}$ and $S^{*}$. Here, $c_{p}$ is the specific heat of sea water and $\rho_{0}$ and $S_{0}$ are constant reference values for density and salinity. For salinity there is no specific physical basis for such a treatment, it must be regarded as a technical device to introduce observed surface values in the model.

Specification of fresh water fluxes allows the salinity field to evolve freely and is a physically better justified condition. It was found that the thermohaline circulation (THC) reacts very sensitively to perturbations in the surface salinity or surface fresh water fluxes under this type of boundary conditions (Bryan 1986; Marotzke and Willebrand 1991; Weaver and Sarachik 1991). Relatively minor perturbations in the fresh water flux can lead to dramatic changes in poleward heat and salt transport, or even a breakdown of the oceanic thermohaline circulation (termed "polar halocline catastrophe" by Bryan 1986). Recent model studies (Zhang et al. 1993; Rahmstorf 1995; Rahmstorf and Willebrand 1995; Lohmann et al. 1996) suggest that the sensitivity under these mixed boundary conditions is overestimated. Also, recent and paleo-oceanographic evidence shows that the sensitivity of the climate system is much smaller. Quite substantial observed perturbations, such as the great salinity anomaly (GSA, Dickson et al. 1988), have not resulted in anything like the major changes predicted under mixed boundary conditions. Even the large input of meltwater into the northern North Altantic during the last deglaciation probably did not result in a complete breakdown of the thermohaline circulation (Lehman and Keigwin 1992). 
The current mode of the thermohaline circulation (THC) is thought to be maintained by a non-linear process involving the poleward transport of warm and saline water to the deep water formation areas in the North Atlantic (Warren 1983). At high-latitudes heat is lost to the cold atmosphere, mainly by evaporation. Evaporation results in relatively small net freshwater flux into the ocean and a relatively high salinity is maintained. A dense water mass is generated that sinks and fills the deep ocean basis. Inflow of surface water into the deep water formation region must compensate the sinking and equatorward transport of deep water thus increasing the poleward transport of saline water. The strong positive feedback between poleward salinity transport and deep sinking (salt transport feedback) will amplify perturbations of this mechanism. Associated with the poleward salt transport is a poleward oceanic heat transport that tends to reduce the meridional surface density gradient and the strength of the thermohaline circulation. This is a negative feedback process that partly compensates for the salt transport feedback (oceanic heat transport feedback).

Besides the oceanic transports, atmospheric processes affect the strength and stability of the THC. A stronger THC results in higher SST and larger oceanatmosphere heat flux in the sinking regions. Atmospheric heat transports tend to maintain the anomalous ocean - atmosphere heat flux because they allow fast horizontal spreading of localized heat anomalies. Higher surface density in the high-latitude oceans and an intensified THC can be the result of this positive feedback (atmospheric heat transport feedback). On the other hand, a strengthening THC diminishes the meridional SST gradient and ultimately the atmospheric heat transport.

Effects of water vapour transport complement the atmospheric heat transport effect. Reduced poleward transport of water vapour implies less fresh water input to high-latitude oceans. The atmospheric latent heat transport increases with temperature but decreases with the meridional temperature gradient. It is thus not immediately clear how the latent heat transport will react to an anomalously strong THC because it is associated with higher temperatures at middle- and highlatitudes as well as a smaller meridional temperature gradient (water vapour transport feedback). Important additional feedbacks exist that are, however, beyond the scope of the present study.

In a coupled ocean - atmosphere system all feedbacks act simultaneously. This represents a major problem in identifying the most important feedbacks for the stability of the THC. The aim of the present model study is to isolate the effects of the individual feedback processes listed above and to compare them quantitatively in a given coupled model. The coupled ocean - atmosphere model, in our case, consists of a three dimensional primitive equation ocean model and an energy balance atmospheric model that contains parametrizations for sensible and latent heat transport. We are going to describe the two model components and the experimental design in the following two sec- tions. The results of the experiments are presented in Sect. 4, followed by discussion and conclusions in the final two sections.

\section{Model}

\subsection{Atmospheric model}

We employ a vertically and zonally integrated energy balance model (EBM) for the atmospheric component in the coupled model. Chen et al. (1995) describe the model in detail.

2.1.1 Basic equations. The model is based on the vertically integrated and zonally averaged thermodynamic energy equation. Kinetic energy and adiabatic terms are neglected.

$\int_{p_{0}}^{0}\left[c_{p} \frac{\partial T}{\partial t}\right] d p=\int_{p_{0}}^{0}[h] d p-\int_{p_{0}}^{0} c_{p} a^{-1} \frac{\partial}{\partial \phi}[F] d p$

Here $p_{0}$ is the pressure at the surface, $c_{p}$ the specific heat capacity of air at constant pressure, $a$ is the Earth's radius, $\phi$ the geographical latitude, and [.] represents a zonal average. The last term on the rhs represents the divergence of the total meridional heat transport composed of sensible and latent heat transports.

The hydrological cycle is included in the model by means of the conservation equation for water vapour $q$

$\int_{p_{\mathrm{o}}}^{0}\left[L \frac{\partial q}{\partial t}\right] d p=g L([E]-[P])-\int_{p_{0}}^{0} c_{p} a^{-1} \frac{\partial}{\partial \phi}\left[F_{l}\right] d p$

Here $E-P$ is the mass flux of fresh water at the surface and $F_{l}$ is the latent heat transport. $L$ is the latent heat of evaporation (Table 1). For the purposes of this study we neglect the storage term on the left hand side and consider a diagnostic balance between meridional divergence of water vapour transport and net fresh water flux.

The internal heating of the atmosphere is given by

$g^{-1} \int_{p_{0}}^{0}[h] d p=\left[R_{\text {top }}\right]-\left[R_{\text {bottom }}\right]+L[E]+[S H]$

with the downward net radiative fluxes at the top, $R_{\text {top }}$, and the bottom, $R_{\text {bottom }}$, of the atmosphere, the sensible heat flux, $S H$, and the latent heat flux, $L E$. The net radiative flux at the top of the atmosphere, $R_{\text {top }}$, can be expressed as

Table 1. Parameters for the atmospheric energy balance model

\begin{tabular}{|c|c|}
\hline$A$ & $213.24 \mathrm{~W} \mathrm{~m}^{-2}$ \\
\hline$B$ & $2.22 \mathrm{~W} \mathrm{~m}^{-2} \mathrm{~K}^{-1}$ \\
\hline$p_{0}$ & $1000 \mathrm{mb}$ \\
\hline$c_{p}$ & $1004 \mathrm{~J} \mathrm{~kg}^{-1} \mathrm{~K}^{-1}$ \\
\hline $1 / \gamma$ & 30 days \\
\hline$r h$ & 0.8 \\
\hline$L$ & $2.5 \times 10^{6} \mathrm{~J} \mathrm{~kg}^{-1}$ \\
\hline
\end{tabular}


$R_{\text {top }}=Q\left(1-\alpha_{p}\right)-I$

where $Q$ is the solar insolation, $\alpha_{p}$ is the planetary albedo and $I$ is the outgoing long-wave radiation. The planetary albedo is specified as a function of latitude and surface air temperature thus incorporating the icealbedo feedback (Sellers 1969). The outgoing longwave radiation is estimated using the parametrization proposed by Budyko (1969), $I=A+B T_{0}$, where $A$ and $B$ are empirical constants (Table 1 ) and $T_{0}$ is the surface temperature. To relate the change of vertically integrated temperature, $\frac{\partial}{\partial t} \int_{p_{0}}^{0} T \frac{d p}{g}$ to changes of surface temperature, we use a formula given by Rennick (1977) where the temperature $T(p)$ is parametrized in terms of $T_{0}$.

We assume that land surfaces have vanishing heat capacity and that the heat flux at the surface vanishes over land. The sum of all heat flux contributions at the surface is

$F_{O A}=f_{0}\left(R_{\text {bottom }}^{0}-S H^{0}-L E^{0}\right)$

where $f_{0}$ is the fraction of the ocean model domain at each latitude and a superscript ${ }^{0}$ denotes fluxes at the air-sea boundary. We assume that the heat fluxes over other parts of the ocean than the Atlantic remain constant in time. The air-sea fluxes are evaluated using linearized bulk formulas.

2.1.2 Transport parametrization. Our aim is to model the climate system in response to perturbations in the high-latitude deep water formation areas. Transient eddies dominate the atmospheric heat transport at these latitudes (Peixóto and Oort 1992). Therefore, we regard the heat transport by the mean meridional circulation and by standing eddies as given and only parametrize the heat transport by transient eddies. The atmospheric response in the equatorial belt will thus be quite unrealistic because the Hadley cell can not react to changes in the oceanic state.

Assuming that eddy fluxes arise from baroclinic instability, the transient eddy fluxes can be parametrized as follows (Green 1970; Stone 1972):

$\overline{\nu^{\prime} T^{\prime}}=-\kappa_{s}\left|a^{-1} \frac{\partial T}{\partial \phi}\right|^{n-1}\left(a^{-1} \frac{\partial T}{\partial \phi}\right)$

$\overline{\nu^{\prime} q^{\prime}}=r h \frac{\partial q_{s}}{\partial T} \overline{\nu^{\prime} T^{\prime}}$

Here $T^{\prime}, q^{\prime}$, and $\nu^{\prime}$ are the deviations of temperature, mixing ratio for water vapour, and meridional velocity from their respective zonal and temporal means $T, q, \nu$. The overbar denotes a zonal and temporal mean. The relative humidity is denoted by $r h$ and $q_{s}(T, p)$ is the staturation mixing ratio. The power law and the diffusion coefficient $\kappa_{s}$ for the sensible heat transport in principle both depend on latitude and vertical stability (Branscome 1983; Stone and Yao 1990). Empirically, $n$ is found to be in the range from 1.6 to 4 (Stone and Miller 1981) and $n=2$ for high-latitudes. For our calculations we choose a constant value of $n=2$.

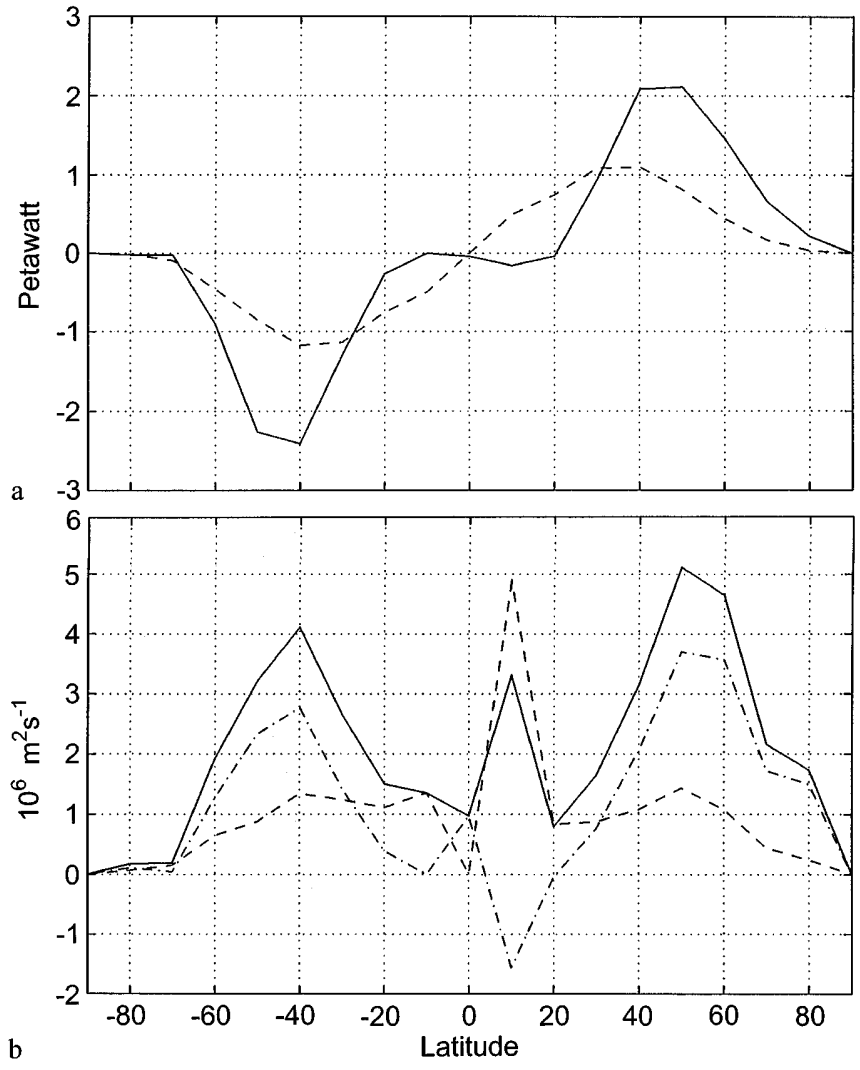

Fig. 1. a sensible (solid) and latent (dashed) northward transports by transient eddies (from Oort and Peixoto 1983), b effective diffusitivities for the total (solid), sensible (dashed), and latent (dotdashed) heat transport calculated from observed transports and meridional temperature gradients

The sensible heat flux is parametrized in terms of the surface temperature because the dependence of the lapse rate on temperature is weak. We tune $\kappa_{s}$ to reproduce the observed transient sensible heat transport (Oort and Peixoto 1983). The coefficient $\kappa_{s}$ reaches $0.9 \times 10^{12} \mathrm{~m}^{3} \mathrm{~s}^{-1} \mathrm{~K}^{-1}$ at $50^{\circ} \mathrm{N}$ and slightly smaller values at Southern Hemisphere mid-latitudes. For comparison with diffusion coefficients given in the literature we show $\kappa_{s}$ normalized by the basic state meridional temperature gradient in Fig. 1. Maximum diffusion coefficients thus computed are $4 \times 10^{6} \mathrm{~m}^{2} \mathrm{~s}^{-1}$ at $40^{\circ} \mathrm{S}$ and $5 \times 10^{6} \mathrm{~m}^{2} \mathrm{~s}^{-1}$ at $50^{\circ} \mathrm{N}$; the diffusivities fall off rapidly towards higher latitudes.

For the latent heat transport we use an analogous approach, namely

$$
\begin{aligned}
& \int_{0}^{p_{0}} \frac{c_{p}}{L} F_{l} d p=\int_{0}^{p_{0}}\left[r h(p) \frac{\partial q_{s}}{\partial T} \overline{\nu^{\prime} T^{\prime}}\right] d p= \\
& -\kappa_{l} r h\left(p_{0}\right) \frac{\partial q_{s}}{\partial T_{0}}\left(p_{0}, T_{0}\right)\left|a^{-1}\left(\frac{\partial T_{0}}{\partial \phi}\right)\right| a^{-1}\left(\frac{\partial T_{0}}{\partial \phi}\right)
\end{aligned}
$$

Here we adopt the surface values for $\frac{\partial q_{s}}{\partial T_{0}}$ and $r h$ because water vapour is concentrated near the surface outside the tropics. Any effects of vertical stratification are subsumed in the diffusion coefficient $\kappa_{l}$ which we 
tune according to observed fluxes, independently of the coefficient $\kappa_{s}$ for sensible heat (Fig. 1).

Both, the sensible and the latent heat transports depend on the meridional gradient of the zonal and vertical mean temperature. However, for the latent transport the gradient is weighted by $\frac{\partial q_{s}}{\partial T_{0}}$ which depends on temperature. The temperature dependence can lead to enhanced latent transports when the local temperature increases while the meridional temperature gradient diminishes. The importance of this effect for climate stability has been pointed out by Weaver (1993).

2.1.3 Response to SST anomalies. To document the behaviour of the atmospheric model in simple cases we consider the equilibrium response of the model to local changes in SST. Without horizontal transports and possible changes in albedo the equilibrium response in surface air-temperature is simply given by

$\Delta T=\frac{\gamma \Delta S S T}{(B+\gamma)}$

where $\gamma=\frac{\partial F_{O A}}{\partial S S T}$ is the sensitivity of the air sea heat flux with respect to $S S T$ anomalies. A typical value for mid-latitudes is $50 \mathrm{~W} \mathrm{~m}^{-2} \mathrm{~K}^{-1}$ (Haney 1971). Because $\gamma$ is much larger than $B\left(=2.22 \mathrm{~W} \mathrm{~m}^{-2} \mathrm{~K}^{-1}\right)$ the surface air temperature would follow SST very closely in this case. However, the horizontal transports will reduce this tendency by distributing $\Delta T$ meridionally away from the forcing region. An example for the distribution of atmospheric temperature anomaly in response to a positive $S S T$ anomaly of $1 \mathrm{~K}$ at $55^{\circ} \mathrm{S}$ is given in Fig. 2a. The local change in air temperature is only $0.32 \mathrm{~K}$ due to divergent anomalous atmospheric heat transports (Fig. 2b) which remove the excess heat and keep the air temperature relatively low compared to $S S T$. South of $55^{\circ} \mathrm{S}$ the transports are smaller than north of the anomaly due to a decline in the diffusivities and in $\frac{\partial q_{s}}{\partial T_{0}}$. The divergence of the latent heat transport results in a reduction in surface net freshwater flux (Fig. 2c) of almost $2 \mathrm{~cm} /$ year at $55^{\circ} \mathrm{S}$.

\subsection{Ocean model}

The ocean model is the Geophysical Fluid Dynamics Laboratory primitive equation model (Pacanowski et al. 1991, 1993). The prognostic variables are potential temperature, salinity, and the internal and external (vertically integrated) velocities. The model is formulated on an Arakawa B-grid with temperature and salinity defined at the centre and the horizontal velocity components defined at the corners of grid boxes. The hydrostatic and Boussinesq approximations are made and surface gravity waves have been eliminated by a rigid lid condition. Subgrid scale processes are parametrized by diffusion using a Laplacian mixing formula-
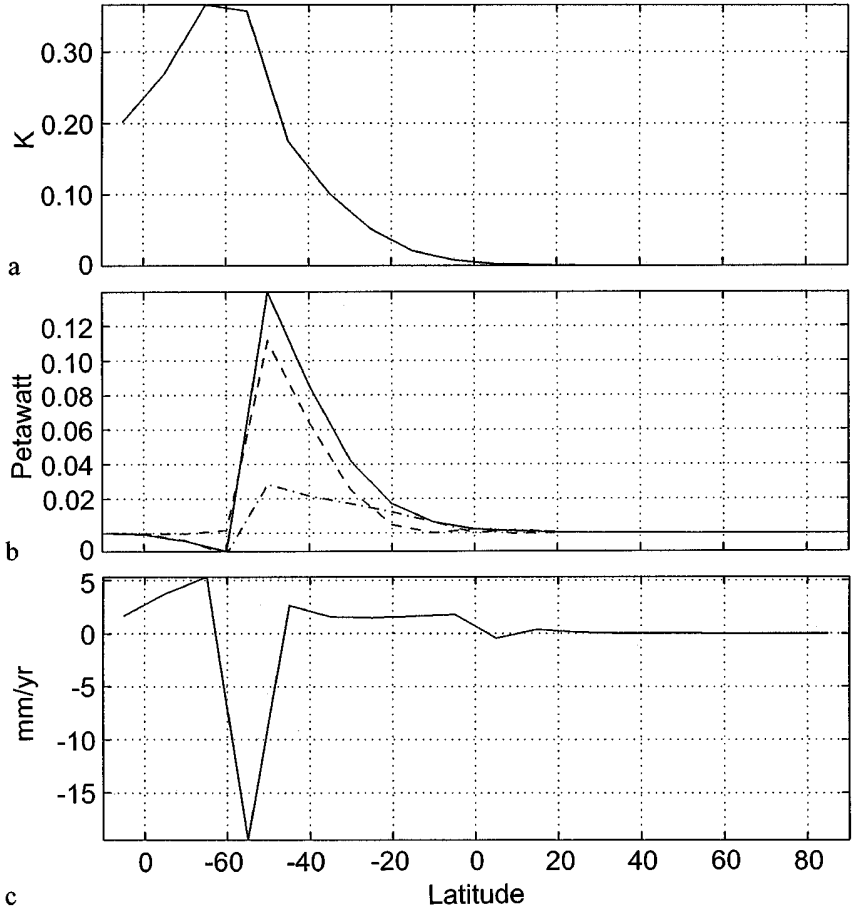

Fig. 2a-c. Equilibrium reponse of the atmospheric EBM to a positive SST anomaly of $1 \mathrm{~K}$ at $55^{\circ} \mathrm{S}$. a anomalous air temperature, b anomalous total (solid), sensible (dashed), and latent (dotdashed) heat transport, c anomalous $P-E$ calculated from Eq. (2.2)

tion with horizontal and vertical viscosities, $A_{M H}=2.0 \times 10^{5} \mathrm{~m}^{2} \mathrm{~s}^{-1}$ and $A_{M V}=10^{-3} \mathrm{~m}^{2} \mathrm{~s}^{-1}$, respectively. The diffusion coefficients for potential temperature and salinity are $A_{H H}=2 \times 10^{3} \mathrm{~m}^{2} \mathrm{~s}^{-1}$ in the horizontal and $A_{H V}=10^{-4} \mathrm{~m}^{2} \mathrm{~s}^{-1}$ in the vertical direction. Convective mixing of tracers is invoked when the density stratification becomes statically unstable. For the time integration we employ the distorted physics approach of Bryan (1984) using a 17.2 fold longer time step for temperature and salinity (0.36 days) than for the velocity field $(30 \mathrm{~min})$.

The model domain is a sector ocean of $74^{\circ}$ width in longitude and a latitudinal extent from $66^{\circ} \mathrm{S}$ to $80^{\circ} \mathrm{N}$. The horizontal resolution is $2^{\circ}$ in both the zonal and meridional directions. The model has 15 levels in the vertical, the grid sizes increases from $30 \mathrm{~m}$ for the first level to $836 \mathrm{~m}$ for the deepest level. The bottom is flat at $5700 \mathrm{~m}$.

All boundaries are insulating for heat and salinity, except for surface where

$$
\begin{aligned}
& \rho_{0} c_{p} A_{V H} \frac{\partial \Theta}{\partial z}=Q \\
& \rho_{0} A_{V H} \frac{\partial S}{\partial z}=(E-P) S_{0}
\end{aligned}
$$

Here $Q$ is the surface heat flux, $E-P$ the net fresh water flux including run-off, and $S_{0}$ a reference salinity. The specification of $Q$ and $E-P$ varies during spin-up and between the experiments and is described in more 
detail in the next section. Besides the thermohaline forcing given by Eq. (2.9) a zonal wind stress drives the circulation in the model. The wind stress is derived from the Hellerman and Rosenstein (1983) annual mean by zonal averaging over the Atlantic. At horizontal boundaries a non-slip condition applies while a free-slip condition is implemented at the bottom.

The ocean receives the zonally averaged fresh water flux, i.e. there is no additional fresh water flux due to runoff from the continents. Only the fresh water that is carried beyond the northern and southern boudaries of the ocean basin are returned to the ocean through runoff at the boundary grid points.

The ocean model includes a simple thermodynamic sea ice component. Changes in sea ice thickness are calculated from the heat balance at the sea ice surface and bottom. The sea ice has no effect on the fresh water flux into the ocean and only reduces the air-sea heat exchange when present. This sea ice model is similar to that used by Maier-Reimer et al. (1993) except that here the surface ice temperature is calculated from the requirement that the heat flux at the sea ice-atmosphere interface vanishes.

\subsection{Coupling of the models}

The resolution of the atmospheric model is $10^{\circ}$ in the meridional direction. Air temperature is defined at the centre of a grid cell at $85^{\circ} \mathrm{N}, 75^{\circ} \mathrm{N}$ etc. Heat flux at the ocean-atmosphere interface is calculated individually at ocean temperature points using linearly interpolated air temperatures in the bulk formulas. The atmosphere model receives the integral heat flux over the area of an atmospheric grid cell. $P-E$ is also defined at the centre of an atmospheric grid cell and is interpolated onto the position of the ocean salinity points. The ocean tracer time step and the atmospheric time step are identical (0.36 days).

\section{Experimental procedure}

\subsection{Spin-up}

The spin-up of the ocean model starts from rest and horizontally homogeneous temperature and salinity distributions. The model is integrated for $8180 \mathrm{y}$ until the zonal integrals of the surface fluxes are equal to the divergence of the meridional transports of heat and salt (Table 2).

The surface heat flux is computed according to Eq. (1.1) where $T^{*}$ is the zonally constant air temperature from Oort (1983). During the first $6800 \mathrm{y}$ of the integration a restoring condition Eq. (1.2) determines the surface fresh water flux and run-off. The reference salinity $S^{*}$ was constructed by zonally averaging the annual mean surface salinity from Levitus (1982) over the Atlantic, excluding the Mediterranean, Hudson Bay, and the Baltic. The restoring time constant $\gamma_{S}{ }^{-1}$ is 30 days. For the rest of the spin-up, observed net fresh
Table 2. Some results for the reference run at the end of spin-up after 8180 years of integration

\begin{tabular}{lc}
\hline Maximum northward ocean heat transport NH/PW & 1.08 \\
Maximum northward ocean heat transport SH/PW & -0.14 \\
Maximum meridional volume transport NH/Sv & 25.5 \\
Maximum meridional volume transport SH/Sv & 0.0 \\
Ocean heat transport at $50^{\circ} \mathrm{S}$ & -0.14 \\
Air. temperature at $55^{\circ} \mathrm{S}$ & 1.4 \\
$\mathrm{SST}$ at $55^{\circ} \mathrm{S}$ & 1.67 \\
Air-sea heat flux at $55^{\circ} \mathrm{S} / \mathrm{W}$ & 5.66 \\
Surface salinity at $55^{\circ} \mathrm{S} / \mathrm{psu}$ & 34.37 \\
Surface density at $55^{\circ} \mathrm{S} /\left(\mathrm{kg} \mathrm{m}^{-3}\right)$ & 27.56 \\
$P-E$ at $55^{\circ} \mathrm{S} /(\mathrm{m} / \mathrm{year})$ & 0.525
\end{tabular}

Ocean volume transports are given in $\mathrm{Sv}\left(1 \mathrm{~Sv}=10^{6} \mathrm{~m}^{3} \mathrm{~s}^{-1}\right)$, and heat transports are given in $10^{15} \mathrm{~W}$. $\mathrm{NH}$ and $\mathrm{SH}$ denote Northern and Southern Hemisphere, respectively

water fluxes from Sellers (1969) were used. The comparison (Fig. 3) of the observed flux and that implied by Eq. (1.2) shows unrealistically large implied net precipitation over Northern Hemisphere mid-latitudes. On the other hand, integrating the model with Sellers (1969) fresh water fluxes from the initial state leads to a thermohaline circulation with sinking in both hemispheres and deep upwelling at the equator. Forcing the ocean to observed surface salinities during an initial period before switching to observed fluxes ensures that the final state of the ocean model contains a thermohaline circulation with deep sinking near the northern boundary. We note that at least two different steady solutions exist for the present model configuration and identically prescribed fresh water fluxes.

The stream function for the zonally integrated mass transport defined by

$\Phi(z)=\int_{z}^{0} d z \int_{\lambda_{W}}^{\lambda_{E}} \nu a \cos (\phi) d \lambda$

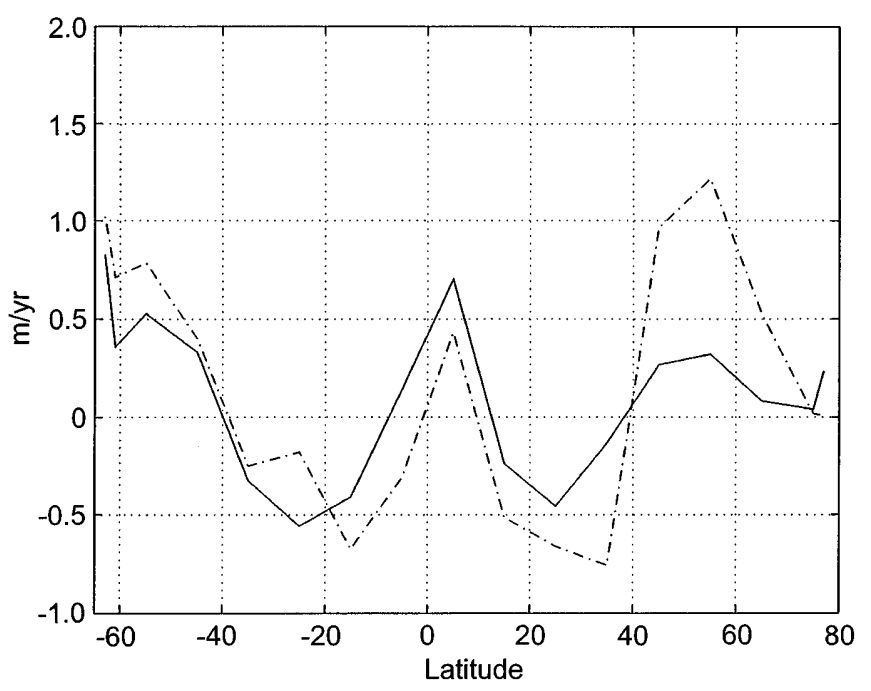

Fig. 3. Net fresh water flux according to Sellers (1969 solid) and diagnosed from the restoring condition on salinity Eq. (1.2). The latter is averaged over the $10^{\circ}$ grid distance of the data. The individual values for the ocean model grid points contain very high peaks in Northern Hemisphere middle-latitudes 


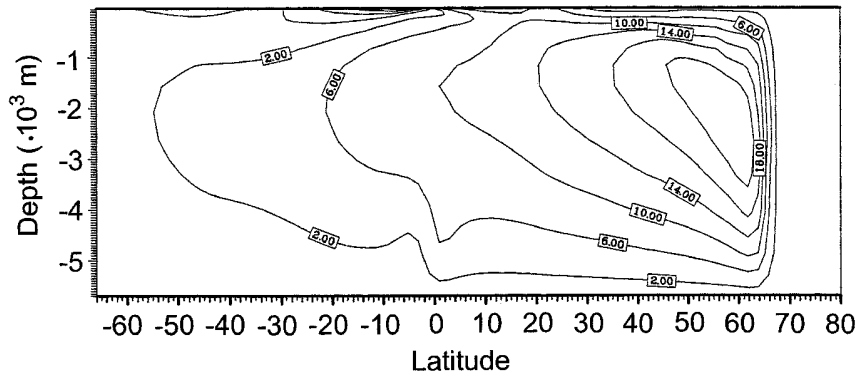

Fig. 4. Stream function for the zonally integrated mass transport at the end of the spin-up. Contour interval: $4 \mathrm{~Sv}$

at the end of the spin-up (Fig. 4) indicates deep sinking at around $60^{\circ} \mathrm{N}$, just south of the region covered with sea ice. Here the water assumes freezing temperature while the upward heat flux by convection prevents sea ice formation. However, once sea ice is present evaporation at the ocean surface is suppressed and a relatively large net fresh water flux enters the ocean compared to south of the ice edge. The resulting low surface salinity prevents deep sinking in ice covered areas. Deep upwelling is almost uniformly distributed south of $60^{\circ} \mathrm{N}$. Closer to the surface, Ekman transport driven cells dominate the zonally integrated flow.

The interior of the subtropical gyres displays the largest surface salinities (Fig. 5). The meridional salinity contrast is relatively small in the Northern Hemisphere. The meridional temperature gradient apparently dominates the meridional overturning (Weaver et al. 1993). In the Southern Hemisphere, with a much smaller transport from the subtropics to higher latitudes, the salinity contrast turns out to be much higher.

The surface heat flux at the end of the spin-up, shown in Fig. 6, features oceanic heat uptake in the tropics and the parts of the subtropics where the Ekman transport is equatorward. Largest heat losses occur in the poleward western boundary currents and their extensions into the interior. There is a pronounced asymmetry between the hemispheres that reflects the northward heat transport associated with the asymmetric overturning circulation. Large heat fluxes also occur near the ice edge, especially in the northeast, where deep convection takes place.

\subsection{Experiments}

The coupled model experiments start from the steady state of the ocean model under mixed boundary conditions. Four experiments were conducted spanning integration periods given in Table 3. They differ from the reference case by a decrease by $0.026 \mathrm{~Sv}$ in runoff from the southern continent. Increased precipitation, homogeneously distributed over the Southern Hemisphere, closes the moisture budget.

It may seem odd to prescribe a Southern Hemisphere perturbation when examining the sensitivity of the thermohaline circulation that is distinguished by northern sinking. However, as we will describe later,

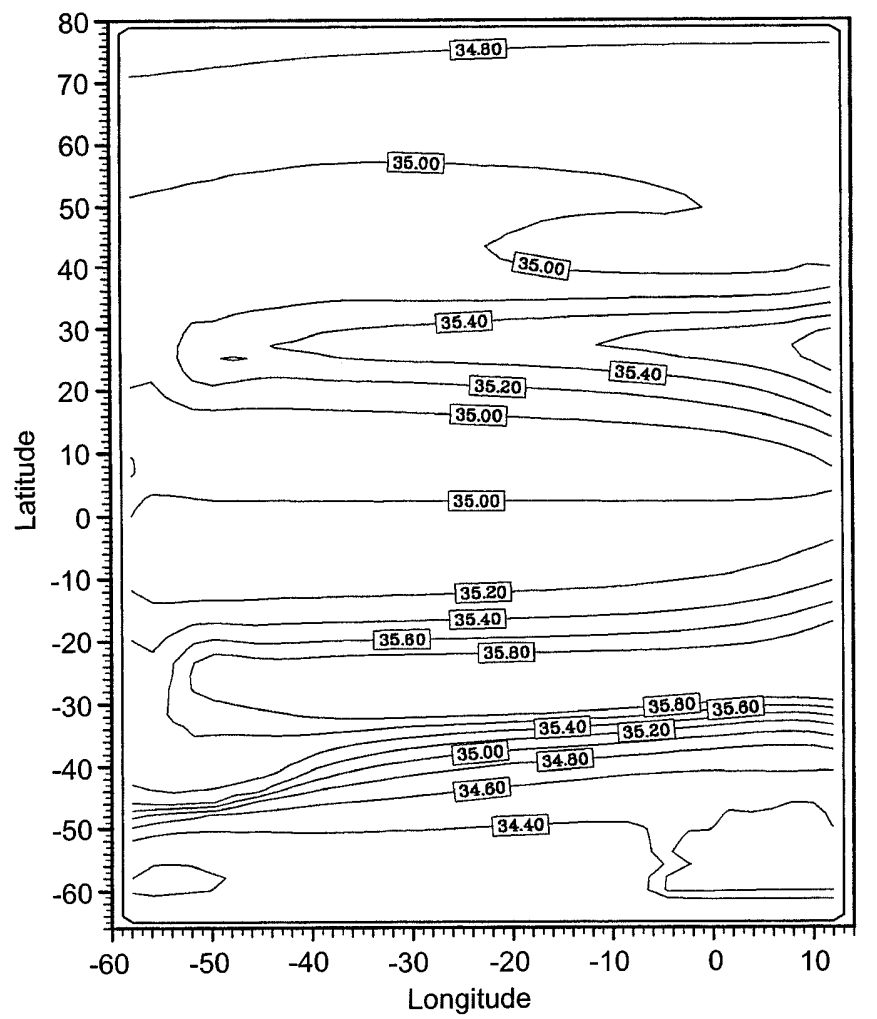

Fig. 5. Surface salinity field at the end of the spin-up. Contour interval: $0.2 \mathrm{psu}$

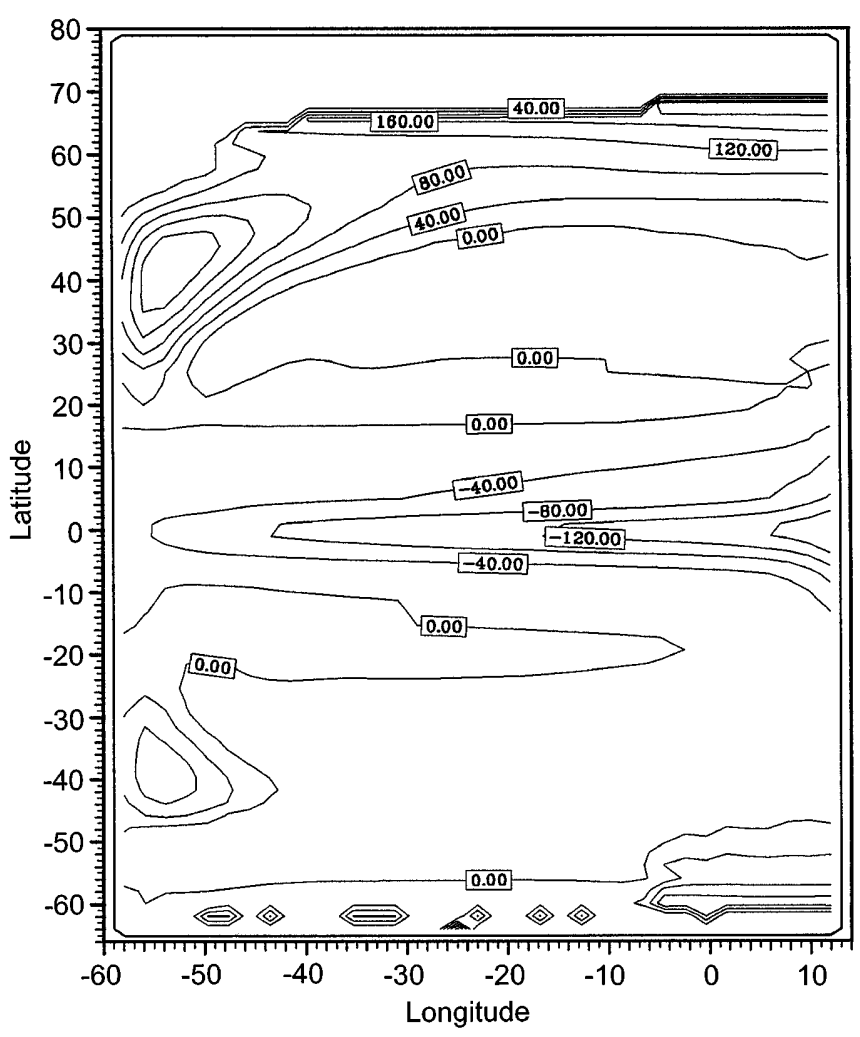

Fig. 6. Surface heat flux at the end of the spin-up. Contour interval: $40 \mathrm{~W} \mathrm{~m}{ }^{-2}$. The position of the ice edge near the northern and southern boundaries is visible as a sharp drop in heat flux 
Table 3. Results for the final state of experiments I (mixed boundary conditions), II (atmosphere without anomalous transports), III (coupled model without fresh water flux anomalies), IV (fully coupled model)

\begin{tabular}{|c|c|c|c|c|}
\hline Experiment & I & II & III & IV \\
\hline Integration period/years & 1906 & 805 & 805 & 2144 \\
\hline Model air temperature & Fixed & Variable & Variable & Variable \\
\hline Model fresh water flux & Fixed & Fixed & Fixed & Variable \\
\hline Model eddy sensible heat transport & - & Fixed & Variable & Variable \\
\hline Model eddy latent heat transport & - & Fixed & Variable & Variable \\
\hline Maximum meridional transport $\mathrm{SH} / \mathrm{Sv}$ & -32.1 & -4.7 & -21.1 & -21.3 \\
\hline Maximum meridional transport $\mathrm{NH} / \mathrm{Sv}$ & 6.7 & 25.1 & 17.8 & 20.1 \\
\hline Maximum northward ocean heat transport SH/PW & -0.786 & -0.209 & -0.441 & -0.417 \\
\hline Maximum northward ocean heat transport NH/PW & 0.435 & 1.036 & 0.811 & 0.847 \\
\hline$\Delta \mathrm{SSS} / \mathrm{psu}$ & 0.62 & 0.41 & 0.67 & 0.67 \\
\hline$\Delta \mathrm{SST} / \mathrm{K}$ & 1.03 & 0.96 & 2.04 & 2.01 \\
\hline$\Delta \rho /\left(\mathrm{kg} \mathrm{m}^{-3}\right)$ & 0.41 & 0.25 & 0.36 & 0.36 \\
\hline Anomalous air sea heat flux at $55^{\circ} \mathrm{S}$ & -8.751 & -0.195 & -2.802 & -2.174 \\
\hline Anomalous air temperature at $55^{\circ} \mathrm{S}$ & - & 0.33 & 1.69 & 1.68 \\
\hline Anomalous sensible heat transport at $55^{\circ} \mathrm{S}$ & - & 0.0 & 0.234 & 0.238 \\
\hline Anomalous latent heat transport at $50^{\circ} \mathrm{S}$ & - & 0.0 & 0.013 & 0.015 \\
\hline Anomalous total atmospheric heat transport at $50^{\circ} \mathrm{S}$ & - & 0.0 & 0.247 & 0.253 \\
\hline Anomalous ocean heat transport at $50^{\circ} \mathrm{S}$ & -0.461 & -0.068 & -0.258 & -0.242 \\
\hline
\end{tabular}

Ocean volume transports are given in $\mathrm{Sv}\left(1 \mathrm{~Sv}=10^{6} \mathrm{~m}^{3} \mathrm{~s}^{-1}\right)$, and heat transports are given in $10^{15} \mathrm{~W} . \Delta \mathrm{SST}, \Delta \mathrm{SSS}$, and $\Delta \rho$ denote the zonal mean difference from the reference run for sur-

under mixed boundary conditions we find a solution with a different steady state where the northern sinking shuts down and an inverse circulation with southern sinking establishes. Furthermore, anomaly experiments in the Northern Hemisphere usually involve substantial changes in sea ice because the basin extends to high northern latitudes where air temperatures are very low. The reaction of the sea ice, which involves latent and sensible heat fluxes, fresh water flux as well as radiation through the ice albedo effect, makes it hard to isolate individual feedback processes.

The experiments employ a hierarchy of coupled models designed to isolate the effects of the individual feedback processes. In the first experiment (I) we continue the spin-up but employ the anomaly in run off at the southern boundary. The experiment is comparable to experiment 3 of Bryan (1986) who used a perturbation in the initial surface salinity field in high southern latitudes to trigger a change in the THC. In the second experiment (II) the ocean and atmosphere models are coupled. However, no anomalous meridional transports are allowed in the atmosphere model. The atmospheric model is given by Eq. (2.1) where, however, the heat transport $F$ remains constant. Also the surface fresh water, flux is kept fixed. A similar system has been considered by Zhang et al. (1993) who used Schopf's (1983) atmospheric model. Because the atmospheric temperature can react to changes in SST, this configuration contains both the oceanic salt and heat transport feedbacks. In experiment III we switch on the atmospheric transports but the ocean model again only receives climatological fresh water fluxes at the surface. The atmospheric model in this experiment is given by Eq. (2.1) with transport parametrization Eqs. face temperature, salinity and density at $55^{\circ} \mathrm{S}$. $\mathrm{NH}$ and $\mathrm{SH}$ denote Northern and Southern Hemisphere, respectively

(2.6) and (2.7). Here, besides the ocean transport feedbacks, the effect of the atmosphere heat transport feedback is included. Rahmstorf and Willebrand (1995) have recently taken a similar approach by coupling an energy balance model to the GFDL ocean circulation model. The transport mechanism in their atmospheric model is a simple two dimensional diffusion for temperature. Finally, in experiment IV, we consider the fully coupled model with the same transport parametrizations, Eqs. (2.6) and (2.7), as in experiment III. Additionally, anomalies of surface fresh water fluxes are determined by Eq. (2.2).

The design of the experiments is such that without anomaly the ocean should receive identical forcing, irrespective of the type of atmospheric model. Thus, the state of the system should remain identical to the equilibrium state at the end of the spin-up. However, small random events, as they can occur associated with convection, can lead to deviations from the steady state because the feedback processes depend on the individual atmospheric model. Rahmstorf (1995) describes climate drift into a new equilibrium after coupling a spun up ocean model to a perfectly flux corrected atmosphere. It is thought that the changes in convection patterns and associated current systems are the primary cause of the transition. Because of the possibility of climate drift that could obscure the response to the prescribed fresh water flux anomaly, we performed reference runs of $\mathrm{O}(100 \mathrm{y})$ for each of the experiments II-IV. However, in none of the cases did we observe a climate drift and all the models remained in the equilibrium that was reached at the end of the spin-up. For simplicity and to spare the expense of lengthy reference runs, we will compare the results of experiments I-IV with the end of the spin-up. 


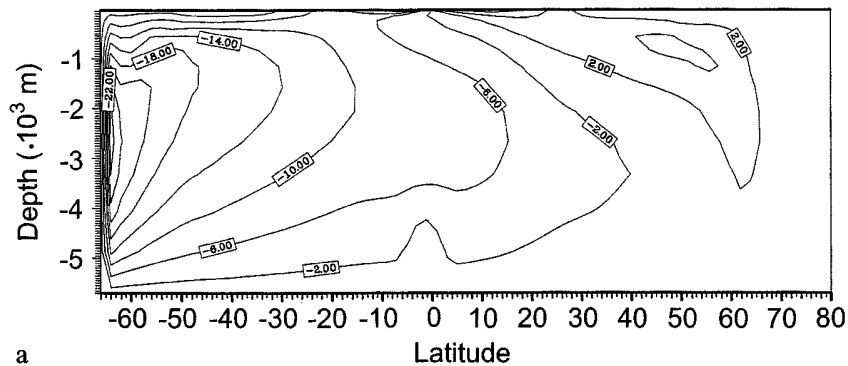

$\mathbf{a}$

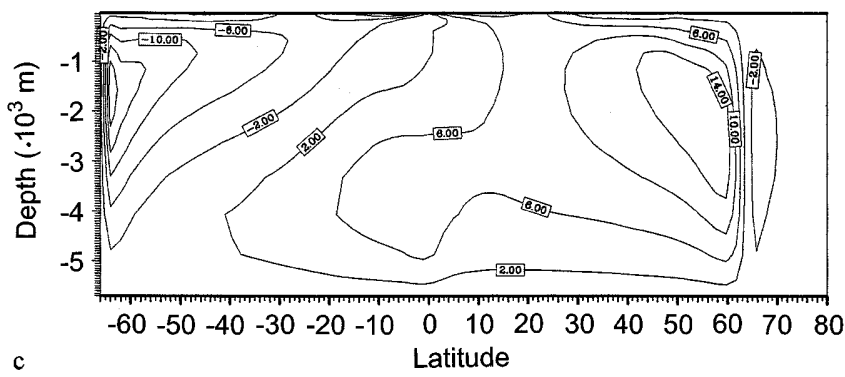

Fig. 7a-d. Stream function for the zonally integrated mass transport $\mathbf{a}$ at the end of experiment I with mixed boundary conditions, $\mathbf{b}$ at the end of experiment II (no anomalous atmospheric

\section{Results}

Table 3 summarizes the main results of the four experiments. With mixed boundary conditions the system assumes a new equilibrium with intense deep sinking near the southern boundary while the deeep sinking in the north ceases. The occurrence of this polar halocline catastrophe under mixed boundary conditions has been reported in several previous studies (e.g. Bryan 1986; Weaver and Sarachik 1991). Only a weak and shallow overturning of slightly more than $5 \mathrm{~Sv}$ remains in the northern half of the basin while deep sinking in the south increases from around $10 \mathrm{~Sv}$ to more than 30 Sv during 1900 years of integration (Fig. 7a). Accordingly, the maximum northward oceanic heat transport shrinks from almost $1 \mathrm{PW}$ to $0.4 \mathrm{PW}$, the latter supported almost exclusively by the low-latitude Ekman transport and high-latitude transport by the wind driven subarctic gyre. Poleward heat transport in the Southern Hemisphere increases to almost 0.8 PW. The oceanic heat transport leads to a final (zonal mean) SST that is up to $1 \mathrm{~K}$ higher in the Southern Hemisphere than at the end of the spin-up. Because the atmospheric temperature is unable to respond to the change in SST, a large anomaly in ocean-atmosphere heat flux develops. The horizontal distribution of surface heat flux (Fig. 8) reflects the large southward heat transport by huge heat losses to the Southern Hemisphere atmosphere in the new equilibrium.

Contrary to SST, surface salinity can change freely in response to the oceanic transport. The surface salinity increases by $0.6 \mathrm{psu}$ at $55^{\circ} \mathrm{S}$ while it decreases north of $20^{\circ} \mathrm{S}$. A local increase in surface salinity by $0.6 \mathrm{psu}$ is a sizeable change that reduces the meridional salinity difference between subpolar and subtropical latitudes from around 1.5 psu to less than 1 psu. With decreasing
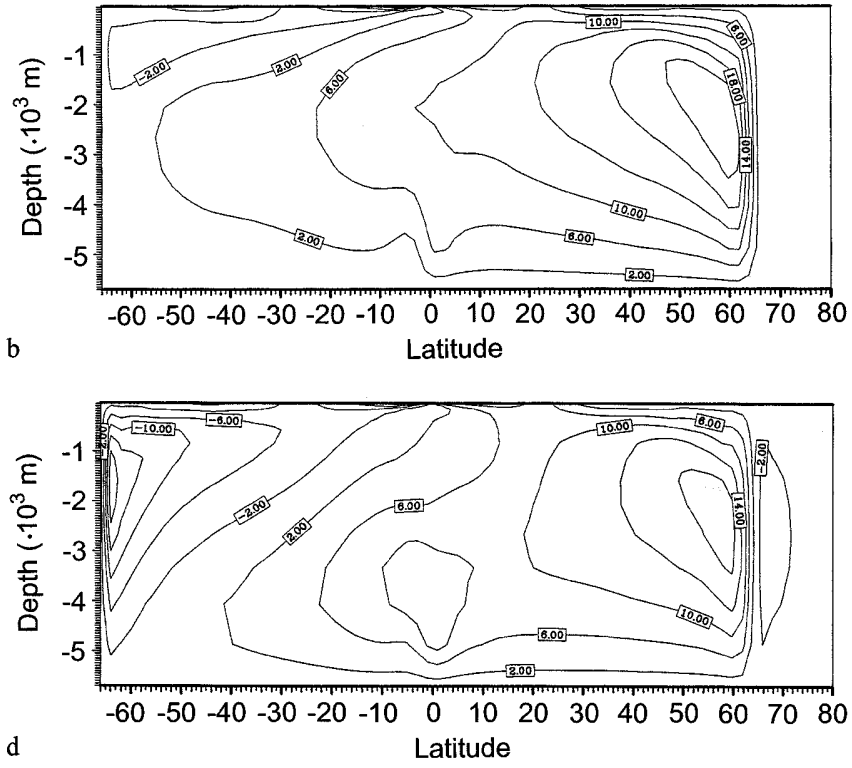

transports), c at the end of experiment III (no fresh water flux anomalies), d at the end of experiment IV (fully coupled). Compare with the reference case (Fig. 4). Contour interval: $4 \mathrm{~Sv}$

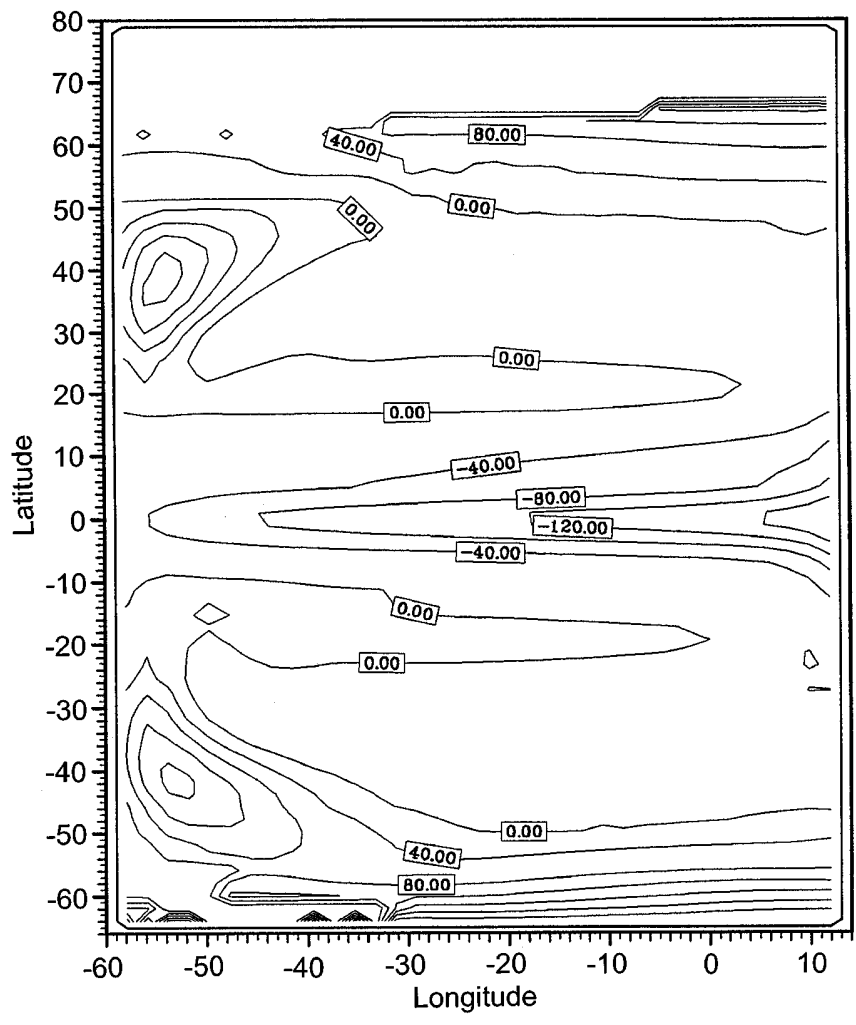

Fig. 8. Ocean surface heat flux at the end of experiment I. This distribution can be compared with the reference heat flux in Fig. 6. Contour interval: $40 \mathrm{~W} \mathrm{~m}^{-2}$

meridional salinity gradient the positive salinity advection feedback diminishes in importance and a new equilibrium can be reached.

When the ocean is coupled to an atmosphere without anomalous transports in experiment II, the reac- 
tion to a change in the southern boundary runoff is substantially altered. Smaller run-off leads to an increase in convection depth and frequency. Vertical mixing brings relatively warm water to the surface. Contrary to experiment I with mixed boundary conditions, here the atmospheric temperature follows SST closely (compare Eq. 2.8). Without anomalous meridional transports the changes in the radiation balance at the top of the atmosphere must balance the changes in surface heat flux. Near the southern sinking region at $55^{\circ} \mathrm{S}$, where albedo remains almost constant, this can only be achieved when the atmospheric temperature increases, thus increasing the long-wave radiation and at the same time reducing the surface heat flux. This last result confirms the findings of Zhang et al. (1993) that the anomalous surface heat fluxes are fundamentally different between mixed boundary conditions and their atmospheric model. Here an increase in atmospheric temperature of $0.33 \mathrm{~K}$ accompanies the rise in local SST by $0.97 \mathrm{~K}$. Taking the zonal mean and the mean over the $10^{\circ}$ meridional extent of computational box of the atmospheric model we find even smaller airsea differences and an anomalous surface heat flux of only $0.2 \mathrm{~W} \mathrm{~m}^{-2}$.

The zonally integrated poleward transport in the ocean increases in response to the changes in the hydrography near the southern boundary, bringing in more warm and saline water from lower latitudes. Contrary to the case with mixed boundary conditions, here both the meridional temperature and salinity gradients relax from their respective initial values and acquire smaller meridional differences at the end of the experiment. Due to the change in fresh water input and to a lesser degree to the small changes in oceanic salt transport, the surface salinity increases by slightly above 0.4 psu in high southern latitudes. Because of the compensating effect on the meridional density gradient, the reaction of the meridional overturning (Fig. 7b) remains rather small with an increase in southward volume transport to $4.7 \mathrm{~Sv}$. The maximum poleward oceanic heat transport in the new equilibrium is sligthly larger than at the end of the spin-up (by $0.07 \mathrm{PW}$ ). This is the change in total poleward heat transport of the coupled system that is consistent with the change in the radiation balance. The vertical temperature difference in the ocean remains almost constant although surface temperatures increase. This is because warmer water sinks from the surface and is carried equatorward in turn.

The horizontal distribution of surface heat flux (Fig. 9) has not changed very much from the end of the spinup (Fig. 6) except for the southern boundary where sea ice has retreated due to the higher temperatures. It should be pointed out that less sea ice tends to destabilize the system because of the larger heat flux from the ocean to the atmosphere. In spite of the sea ice effects the system in experiment II appears to be extremely stable.

In experiment III atmospheric transports distribute horizontally the anomalous heat that the atmosphere receives from the ocean near the southern boundary.

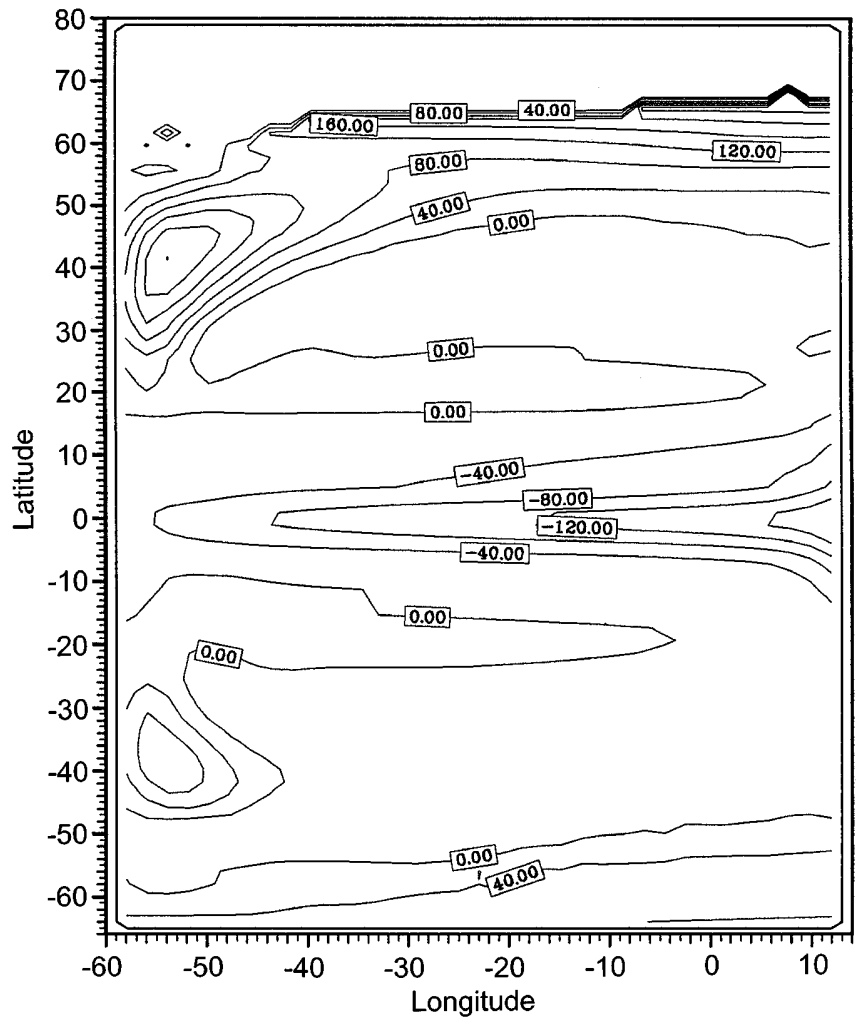

Fig. 9. Ocean surface heat flux at the end of experiment II without anomalous atmospheric heat transports. The distribution is very similar to the reference heat flux in Fig. 6. Largest differences are present near the southern boundary where sea ice almost vanishes in experiment II. Contour interval: $40 \mathrm{~W} \mathrm{~m}^{-2}$

The anomalous atmospheric transport (Fig. 10a) is far more efficient in transporting the anomaly equatorward than poleward, a consequence of sharply decreasing diffusivities south of $70^{\circ} \mathrm{S}$ (Fig. 1b). In contrast to the SST anomaly experiment in Sect. 2 (Fig. 2) the atmospheric response here encompasses an increased northward heat transport in the Northern Hemisphere. Here the meridional air temperature gradient increases as the poleward oceanic heat transport weakens (Table 3 ). The anomalous atmospheric transport is northward except for the small transports poleward of the largest SST anomalies in the south and north. It is opposed to the changes in oceanic heat transport (Fig. 10b) and of similar magnitude except near the equator where our transport parametrization is unable to produce changes in the Hadley circulation.

The new SST equilibrium at $55^{\circ} \mathrm{S}$ lies $2 \mathrm{~K}$ higher than at the end of the spin-up and the atmospheric temperature increases by almost $1.7 \mathrm{~K}$. The air-sea difference of $0.3 \mathrm{~K}$ is much bigger than in experiment II and the resulting anomalous surface heat flux over the $10^{\circ}$ wide latitude belt centred at $55^{\circ} \mathrm{S}$ increases to almost $3 \mathrm{~W} \mathrm{~m}^{-2}$. However, this is still much smaller than with mixed boundary conditions where the air-sea temperature difference at $55^{\circ} \mathrm{S}$ amounts to almost $1 \mathrm{~K}$ at the end of the experiment. The horizontal distribution of surface heat flux for experiment III is shown in Fig. 


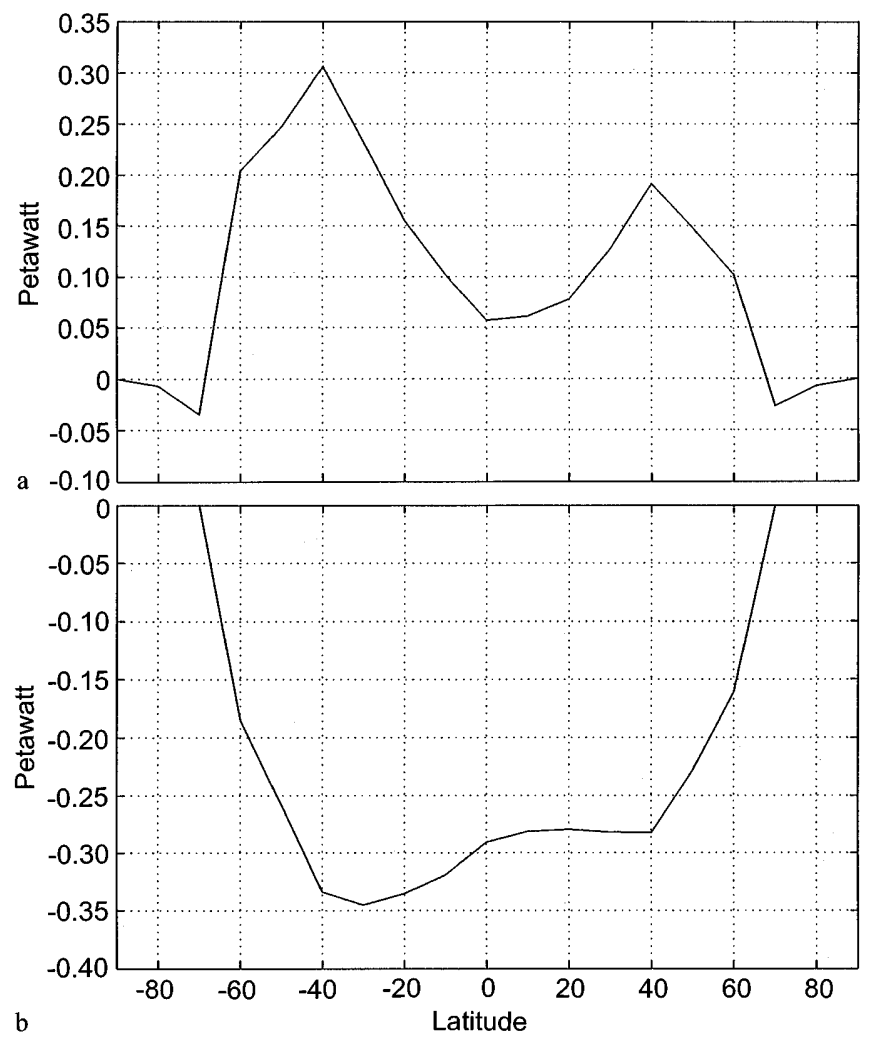

Fig. 10. a Anomalous atmospheric heat transport in experiment III, b difference in the oceanic northward heat transport between experiment III and the end of the spin-up

11. The most pronounced changes compared to the reference case (Fig. 6) are an increased oceanic heat loss in the western boundary current area of the southern subtropical gyre and a somewhat reduced heat loss in its Northern Hemisphere counterpart.

The oceanic mass transport at the end of the integration is shown in Fig. 7c. The deep sinking near the southern boundary increases, driving a southern overturning cell that reaches $21 \mathrm{~Sv}$ after 805 years. The ocean has not reached a completely steady state yet but the results from experiment IV (later) confirm that the coupled model will, however, not drift into the steady state under mixed boundary conditions. Neither will it drift into a symmetric state with strong upwelling at the equator. Instead, there is still deep sinking near $60^{\circ} \mathrm{N}$ and North Atlantic Deep Water (NADW) fills most of the deep basin in the model. However, the rate of NADW formation is somewhat weaker (17 Sv) than at the end of the spin-up (26 Sv) and also weaker than in experiment II without anomalous atmospheric transports.

In experiment IV we discriminate between sensible and latent heat transport in the atmosphere. The divergence of the latent heat transport yields the anomaly of the net fresh water flux at the ocean-atmosphere interface. The components of the anomalous atmospheric heat transport at the end of the experiment $(2144 \mathrm{y})$ are shown in Fig. 12. The anomalous latent heat transport is quite large at low-latitudes. This is a conse-

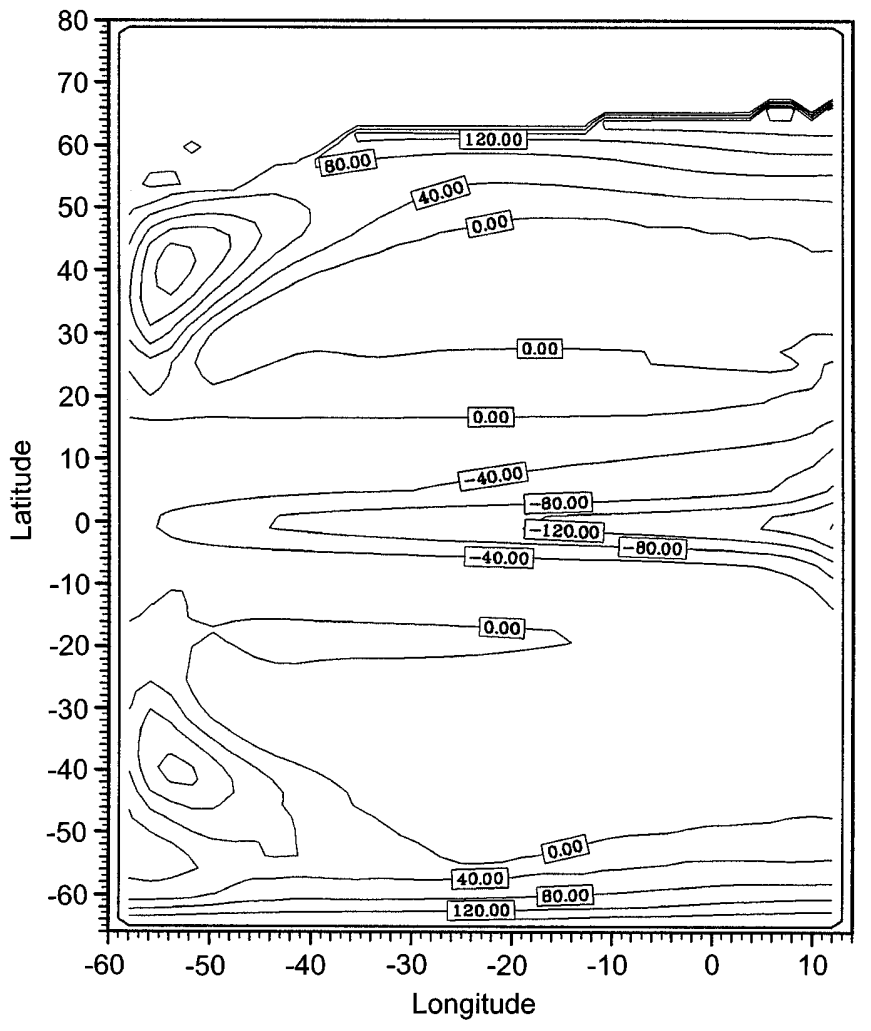

Fig. 11. Ocean surface heat flux at the end of experiment III. Contour interval: $40 \mathrm{~W} \mathrm{~m}^{-2}$
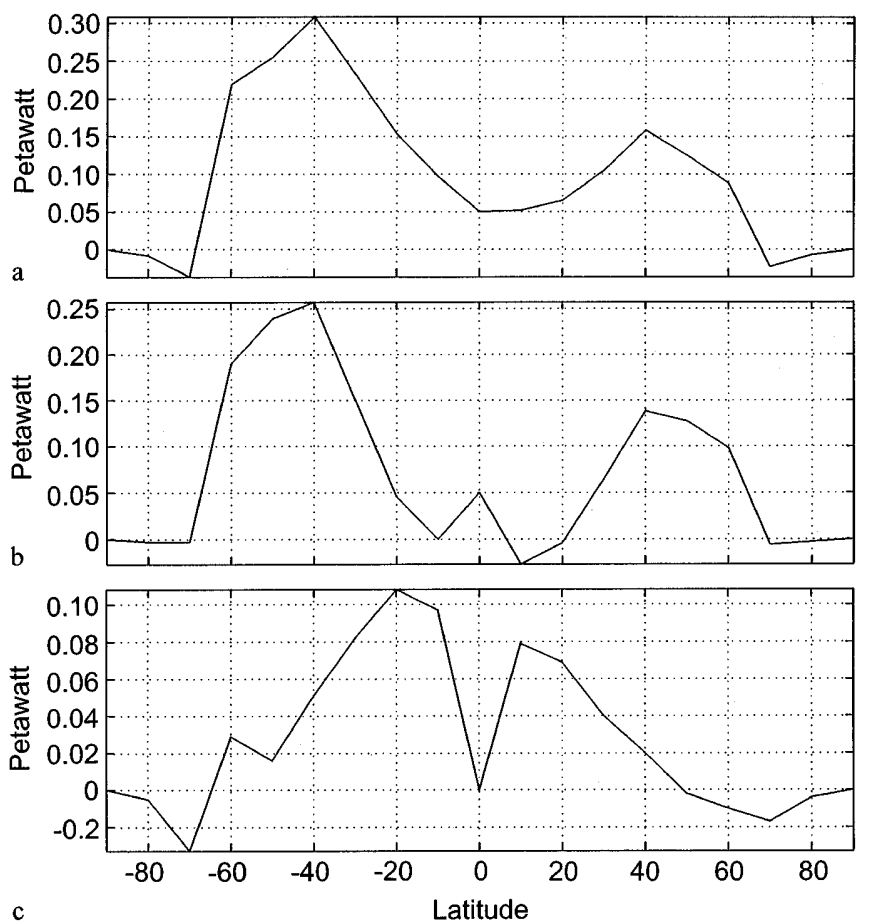

Fig. 12a-c. Components of the anomalous northward atmospheric heat transport in experiment IV. a total, b sensible, c latent heat transport 


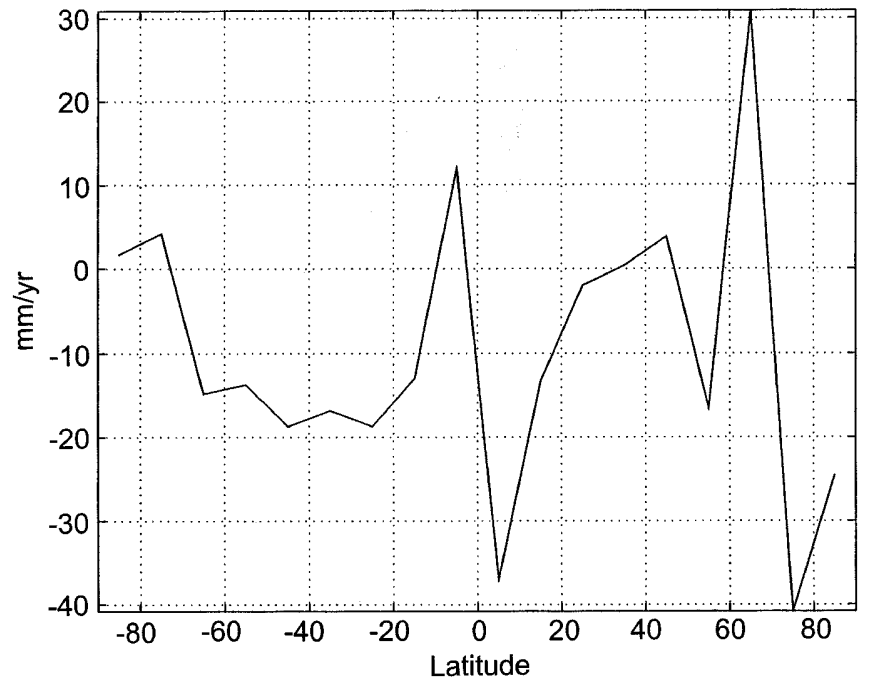

Fig. 13. Deviation of the surface fresh water flux in experiment IV from the observed ditribution used for the reference case. Net precipitation decreases by $4 \mathrm{~cm} /$ year near the southern ocean boundary. This reinforces the tendency towards southern sinking in this experiment

quence of the temperature dependence of the specific humidity that enters the transport parametrization Eq. (2.7). By the same token, the anomalous latent heat transport is only a small fraction (less than $10 \%$ ) of the total atmospheric transport at $55^{\circ} \mathrm{S}$.

However, including water vapour in the atmospheric model not only influences the heat transport but also the thermohaline forcing for the ocean (Fig. 13). Net fresh water flux decreases at $65^{\circ} \mathrm{S}$ due to increased evaporation because of higher SST. The atmosphere carries water vapour north and south leading to larger precipitation at $55^{\circ} \mathrm{S}$ and $75^{\circ} \mathrm{S}$. Between $45^{\circ} \mathrm{S}$ and $25^{\circ} \mathrm{S}$ the net fresh water flux into the ocean is slinghtly reduced while it increases in the Northern Hemisphere between $15^{\circ} \mathrm{N}$ and $65^{\circ} \mathrm{N}$. It is conceivable that the large-scale northward water transport and the corresponding precipitation would favour southern sinking and limit northern sinking. However, the change in the net fresh water flux is very small compared to the change in runoff that we impose from the beginning of the experiment. Therefore, the changes in oceanic circulation compared to experiment III remain small (Table 3) and are mostly due to the different integration periods. As in experiment III we observe the spin-up of a southern overturning cell (Fig. 7d) with $21 \mathrm{~Sv}$ equilibrium transport as in the previous case.

\section{Discussion}

These results confirm the extreme sensitivity to perturbations of the surface fresh water flux with mixed boundary conditions that has been found in previous studies. The sensitivity is due to the positive salinity advection feedback that the system accommodates un- der mixed boundary conditions. Other important feedback processes, however, are neglected or misrepresented with mixed boundary conditions. The constant air temperature leads to large ocean - atmosphere heat fluxes that severely reduce the oceanic heat advection feedback that would otherwise counteract the salinity advection feedback. Since the air temperature is fixed, there is no change in the radiation balance at the top of the atmosphere. Assuming atmospheric equilibrium we conclude that large horizontal heat transports exist in the model atmosphere that keep the temperature fixed in spite of large ocean-atmosphere fluxes. Considering the results with more complete atmospheric models these fluxes seem to be unrealistically large. The total heat transport in the coupled system is constant in this model. Large changes in atmospheric transports thus require large but opposite changes in oceanic transport. (Compare Fig. 14 where the anomalous ocean heat transports for our experiments are summarized.)

Experiment II allows an oceanic heat advection feedback as the atmosphere can respond to changes in SST by adjusting net long wave radiation to space. Here the situation is more complicated because of changes in albedo (ice-albedo feedback) and in sea ice distribution. The radiation balance at the top of our model atmosphere is presented in Fig. $15 \mathrm{a}$. At $65^{\circ} \mathrm{S}$ radiation to space increases locally by more than $5 \mathrm{~W}$ $\mathrm{m}^{-2}$ due to an increase in air temperature of $6 \mathrm{~K}$ and a change in albedo. At this latitude a retreat in sea ice increases air - sea exchange considerably. At other latitudes, except for the Northern Hemisphere counter-
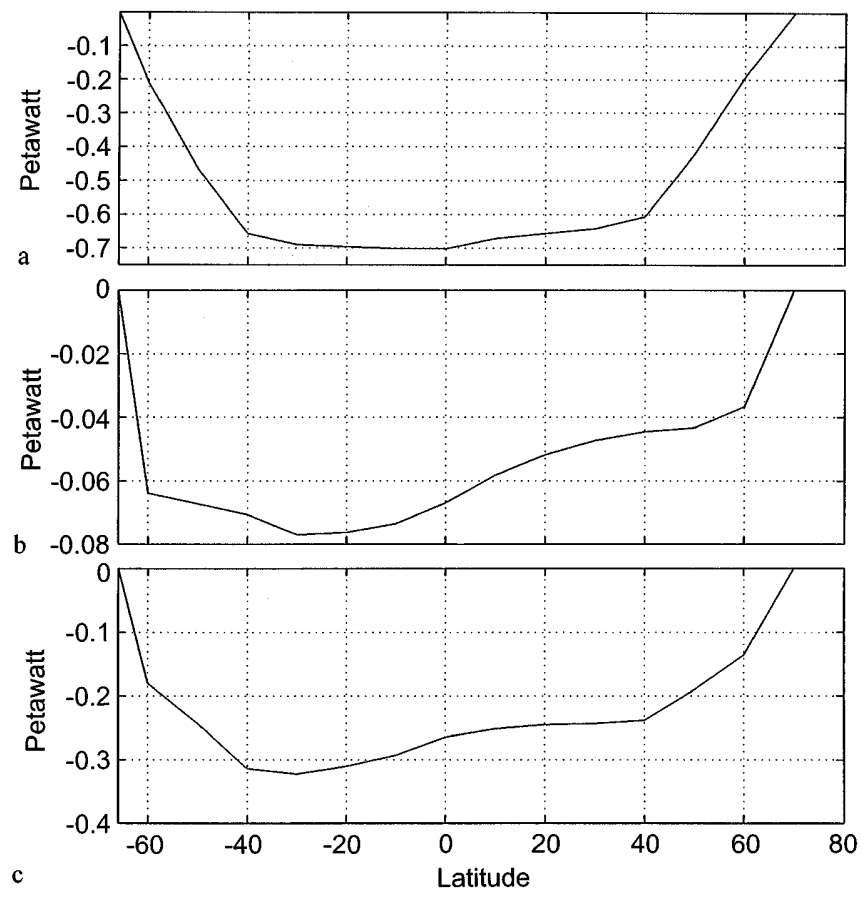

Fig. 14a-c. Summary of the anomalous northward heat transports in the ocean for experiments a I, b II, c IV. The heat transport in experiment III (shown in Fig. 10b) is virtually identical with experiment IV 


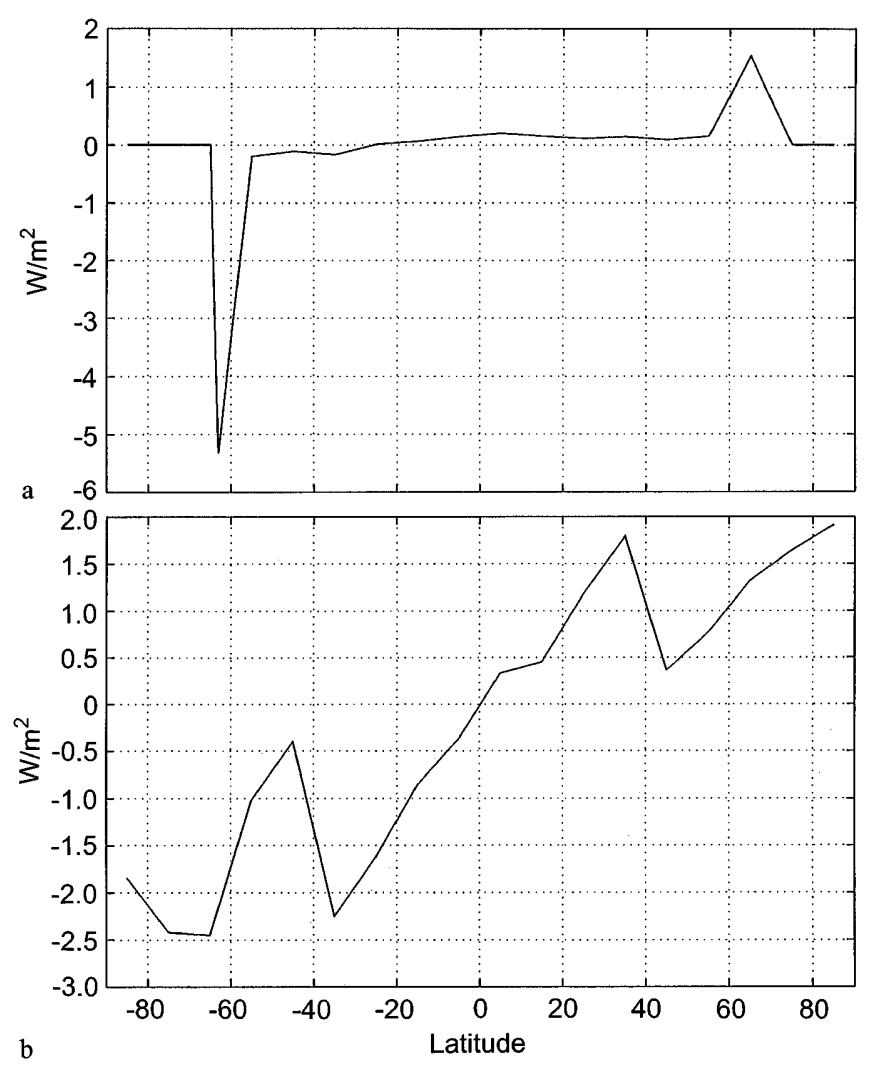

Fig. 15. a Change in the radiation balance at the top of the atmosphere during experiment II, $\mathbf{b}$ change in the radiation balance at the top of the atmosphere during experiment III

part at $65^{\circ} \mathrm{N}$, the changes in air temperature are much smaller and overall the changes in the radiation balance can be regarded as small. Since there are no anomalous atmospheric transports, the radiation balance limits the changes in oceanic heat transport in the steady state. Thus the oceanic overturning is very stable in this case and the deviations from the reference case must remain small. An atmosphere without anomalous transports of its own makes the coupled system less sensitive compared to mixed boundary conditions.

This result is similar to findings by Zhang et al. (1993) and Mikolajewicz and Maier-Reimer (1994). Zhang et al. (1993) couple a zero heat capacity model without anomalous horizontal transports to an ocean GCM. They were unable to induce a polar halocline catastrophe in spite of a perturbation of high latitude surface salinity that causes a breakdown of the THC under mixed boundary conditions. Zhang et al. (1993) show that their atmospheric model is equivalent to mixed boundary conditions where SST is damped towards a modified reference temperature (see their Eq. (4)) and the restoring time scale for SST is increased to 300 days. Accordingly, Mikolajewicz and Maier-Reimer (1994) find increasing stability of the THC under mixed boundary conditions when they increase the damping time scale for SST from 2 months over 3 and 5 months to 200 months. Tziperman et al. (1994) and Power and Kleeman (1994) report similar results.
With anomalous atmospheric transports the changes in oceanic transports can be larger than in experiment II (Fig. 14) although the radiation balance might not be drastically different from before. Figure $15 \mathrm{~b}$ shows that the change in the radiation balance varies between -2 and $2 \mathrm{~W} \mathrm{~m}^{-2}$ in the equilibrium state of experiment III. These numbers indicate a small change in the total heat transport of the coupled system. However, as we have demonstrated already (Fig. 10) the transports in the atmosphere and the ocean are in opposite directions and of comparable magnitude over most of the domain. This mimics the behaviour of coupled GCMs (Manabe and Bryan 1985; see also Weaver 1993 for a discussion of the consequences of this property) where ocean and atmosphere transports tend to cancel each other out such that the total heat transport of the climate system remains fairly constant. Therefore, atmospheric transports allow relatively large changes in the oceanic transports and tend to be destabilizing for a given mode of oceanic overturning. However, the stability is still larger than under mixed boundary conditions where the constant air temperature requires atmospheric transports that are far too large and must be completely compensated for by the oceanic transports.

A somewhat similar configuration for the coupled system as in our experiment III has been examined by Rahmstorf and Willebrand (1995, hereafter RW). They use a boundary condition for SST that is equivalent to running a coupled model with an atmospheric energy balance model with diffusive horizontal heat transports. The transport parametrization is based on an estimate of the realistic lifetime of SST anomalies. For a $1000 \mathrm{~km}$ scale RW cite a heat flux sensitivity of 10-30 $\mathrm{W} \mathrm{m}{ }^{-2} \mathrm{~K}^{-1}$ (Anderson and Willebrand 1992). Adopting a sensitivity at the lower end of this range, RW arrive at a constant diffusion coefficient of $2 \times 10^{6} \mathrm{~m}^{2} \mathrm{~s}^{-1}$ that is comparable to the diffusivities used in experiment III and IV (compare Fig. 1). RW stress that their coupled system is less sensitive to perturbations of the fresh water balance than the ocean model under mixed boundary conditions. We can confirm this finding with our coupled model. However, the changes in the oceanic circulation are smaller in RW's case. Calculations using a coupled box model (Lohmann et al. 1996) indicate that a possible explanation may be RW's assumption that anomalous atmospheric transport only occurs over the oceans. On the other hand, we assume instantaneous heat exchange in the zonal direction and thus probably overestimate the ability of the atmosphere to react to local perturbations in SST. The same box model calculations also show that the basic state, characterized by meridional temperature and salinity differences and strength of the overturning, is very important for the stability of the THC. By considering a fresh water flux perturbation in the Southern Hemisphere, we deal with a basic state with weak meridional overturning which contributes to the sensitivity of the THC.

As in experiment II, sea ice effects contribute to the sensitivity of the THC. We apply the perturbation in 
the fresh water budget near the southern boundary where sea ice covers a smaller area than in the Northern Hemisphere. Therefore, the changes in the radiation balance at the top of the atmosphere in experiments II and III remain rather small and sea ice effects are not crucial in determining the overall sensitivity of the system. However, we observe large sea ice effects perturbations near the northern boundary. These results will be reported in a subsequent study.

A new feature of our coupled ocean-atmosphere model is the water cycle that the stationary water vapour Eq. (2.2) admits. The fresh water exchange can be another positive feedback (Nakamura et al. 1994) when increasing oceanic heat transport is associated with decreasing atmospheric water vapour transport and reduced precipitation in high-latitudes. However, in our experiments the changes in precipitation turned out to be a rather minor effect that does not significantly affect the stability of the thermohaline circulation. It should also be noted that the temperature dependence of the saturation vapour pressure in Eq. (2.7) can reverse this behaviour of the latent heat transport. A reduced meridional gradient in air temperature that is associated with higher temperatures at mid-latitudes can result in an increased water vapour transport and higher precipitation in high-latitudes (Tang and Weaver 1995). This would constitute a negtive feedback. We did not observe a negative feedback in experiment IV, mainly because large changes in air temperature are rather localized over the sinking region in the Southern Hemisphere where the air temperature and the temperature dependence of the saturation vapour pressure are small.

In a box model for the Atlantic and the Northern Hemisphere atmosphere Nakamura et al. (1994) find a strong positive feedback between the meridional atmospheric transport of moisture and high-latitude sinking. The atmospheric transports across the boundary between their two atmospheric boxes at $35^{\circ} \mathrm{N}$ are parametrized in a similar way to Eq. (2.7). However, the fresh water flux is multiplied by a factor $A_{t}=3$ that corrects for the moisture that is taken up from the ocean south of $35^{\circ} \mathrm{N}$ and precipitates over land (and enters for ocean through runoff) north of $35^{\circ} \mathrm{N}$. The crude meridional resolution used by Nakamura et al. (1994) possibly increases the sensitivity. Due to the strong temperature dependence of the moisture transport, most additional moisture that moves northward across $35^{\circ} \mathrm{N}$ in the atmosphere will not reach the high-latitude oceans and thus not contribute to a change in the THC. Furthermore, due the crude resolution of the 3box ocean model SST and latent heat flux changes at low-latitudes are overestimated. On the other hand, our model ignores the runoff that increases the Atlantic fresh water input beyond the zonal average over a latitude circle. This artificially reduces the sensitivity of our model and a better representation of the runoff into the Atlantic is desirable.

\section{Conclusions}

In this study we have examined the sensitivity of the thermohaline circulation in a hierarchy of idealized coupled atmosphere-ocean models. We have systematically investigated the influence of atmospheric heat and moisture transport on the oceanic circulation. The response of the coupled system depends crucially on the feedbacks that the coupled system includes. With only the salinity transport feedback present (mixed boundary conditions) the system becomes very sensitive to high-latitude salinity perturbations. The oceanic heat transport feedback that enters with a zero heat capacity model of the atmosphere largely offsets the positive salinity transport feedback.

The radiation balance at the top of the atmosphere determines the total transport of the climate system in a steady state while the air-sea heat exchange governs the partition of the transports among ocean and atmosphere. The main effect of a zero heat capacity model is to reduce the change in air-sea heat flux in an anomaly experiment compared to mixed boundary conditions (Zhang et al. 1993). Thus the oceanic as well as atmospheric heat transports remain closer to their reference values, resulting in a stable and rather insensitive system. The inclusion of the atmospheric heat transport feedback results in air-sea heat fluxes that lie in between the two extremes given by mixed boundary conditions and the zero heat capacity model. The water vapour transport provides another mechanism that influences the stability of the water column and thus the air-sea heat exchange. It is comparable to other processes, as for example the strength of the surface wind, that influence the oceanic mixed layer. We found this effect to be rather small. However, final evaluation clearly requires a more realistic modelling of the hydrological cycle.

An atmospheric component that realistically describes the anomalous heat transports is essential for adequate modelling of ocean climate variability. As a first step to better reproduce the sensitivity of the climate system to long term changes in the thermohaline boundary conditions we have introduced an EBM with diffusive meridional heat and water vapour transports that are tuned such that the observed transports by transient eddies are reproduced. While we think that this provides an improvement for the treatment of oceanic variability on long time scales, important processes are still not captured. For example, the effective transport by transient eddies depends on the static stability of the atmosphere that is affected when large changes in SST occur. The role of atmospheric fresh water transports between ocean basins (Stocker et al. 1992) and the uncertainty in the amount of runoff from the continents indicate that a simple atmospheric model is needed that resolves meridional as well as zonal transports and takes certain land processes into account. 


\section{References}

Anderson DLT, Willebrand J (1992) Recent advances in modelling the ocean circulation and its effects on climate. Rep Prog Phys 55:1-37

Branscome LE (1983) A parametrization of transient eddy heat flux on a betaplane. J Atmos Sci 40:2508-2521

Bryan K (1984) Accelerating the convergence to equilibrium of ocean-climate models. J Phys Oceanogr 14:666-673

Bryan FO (1986) High-latitude salinity effects and interhemispheric thermohaline circulation. Nature 323:301-304

Budyko MI (1969) The effect of solar radiation variations on the climate of the earth. Tellus 21:611-619

Chen D, Gerdes R, Lohmann G (1995) A 1-D energy balance atmospheric model developed for ocean modelling. Theoret Appl Climatol (in press)

Dickson RR, Meincke J, Malmberg S, Lee A (1988) The "Great Salinity Anomaly" in the northern North Atlantic 1968-82. Progr Oceanogr 20:103-151

Green JSA (1970) Transfer properties of large-scale eddies and the general circualtion of the atmosphere. Q J R Meteorol Soc $96: 157-185$

Haney RL (1971) Surface thermal boundary conditions for ocean circulation models. J Phys Oceanogr 1:241-248

Hellerman S, Rosenstein M (1983) Normal monthly wind stress over world ocean with error estimates. J Phys Oceanogr 13:1093-1104

Lehman SJ, Keigwin LD (1992) Sudden changes in North Atlantic circulation during the last declaration. Nature 356:757762

Levitus S (1982) Climatological atlas of the world ocean. NOAA Prof Pap 13, US Department of Commerce, NOAA, Washington DC, $173 \mathrm{pp}$

Lohmann G, Gerdes R, Chen D (1996) Stability of the thermohaline circulation in a simple coupled model. Tellus (in press)

Maier-Reimer E, Mikolajewicz U, Hasselmann K (1993) Mean circulation of the Hamburg LSG OGCM and its sensitivity to the thermohaline surface forcing. J Phys Oceanogr 23:731757

Manabe S, Bryan K (1985) $\mathrm{CO}_{2}$-induced change in a coupled ocean-atmosphere model and its paleoclimatic implications. J Geophys Res 90:11689-11707

Marotzke J, Willebrand J (1991) Multiple equilibria of the global thermohaline circulation. J Phys Oceanogr 21:1372-1385

Mikolajewicz U, Maier-Reimer E (1994) Mixed boundary conditions in OGCMs and their influence on the stability of the model's conveyor belt. Rep 130, Max-Planck-Institut für Meteorologie, Hamburg

Nakamura M, Stone PH, Marotzke J (1994) Destabilization of the thermohaline circulation by atmospheric eddy transports. J Clim 7:1870-1882

Oort AH (1983) Global atmospheric circulation statistics, 19581973. NOAA Prof Pap 14, Government Printing Office, Washington, D.C.

Oort AH, Peixoto JP (1983) Global angular momentum and en- ergy balance requirements from observations. Adv Geophys $25: 355-490$

Pacanowski RK, Dixon K, Rosati A (1991, 1993) The GFDL modular ocean model user's guide, GFDL Ocean Group Techn Rep 2, Geophysical Fluid Dynamics Laboratory/Princeton University, Princeton, USA

Peixóto JP, Oort AH (1992) Physics of climate. American Institute of Physics, New York

Power SB, Kleeman R (1994) Surface heat flux parameterization and the response of ocean general circulation models to highlatitude freshening. Tellus 46A:86-95

Rahmstorf S (1995) Climate drift in an ocean model coupled to a simple, perfectly matched atmosphere. Clim Dyn (in press)

Rahmstorf S, Willebrand J (1995) The role of temperature feedback in stabilising the thermohaline circulation. J Phys Oceanogr 25:787-805

Rennick MA (1977) The parametrization of tropospheric lapse rates in terms of surface temperature. J Atmos Sci 34:854862

Schopf P (1983) On equatorial waves and El Niño. II: effects of air-sea thermal coupling. J Phys Oceanogr 13:1878-1893

Sellers WD (1969) A global climate model based on the energy balance of the earth-atmosphere system. J Appl Meteorol 8:392-400

Stocker TF, Wright DG, Mysak LA (1992) A zonally averaged, coupled ocean-atmosphere model for paleoclimate studies. J Clim 5:773-797

Stone PH (1972) A simplified radiative-dynamical model for the static stability of rotating atmospheres. J Atmos Sci 29:405418

Stone PH, Miller DA (1980) Empirical relations between seasonal chnges in meridional temperature gradients and meridional fluxes of heat. J Atmos Sci 37:1708-1721

Stone PH, Yao M-S (1990) Development of a two-dimensional zonally averaged statistical-dynamical model. Part III: the parameterization of the eddy fluxes of heat and moisture. J Clim $3: 726-740$

Tang B, Weaver AJ (1995) Climate stability as deduced from an idealized coupled atmosphere-ocean model. Clim Dyn (in press)

Tziperman E, Toggweiler JR, Feliks Y, Bryan K (1994) Instability of the thermohaline circulation with respect to mixed boundary conditions: is it really a problem for realistic models? J Phys Oceanogr 24:217-232

Warren BA (1983) Why is no deep water formed in the North Pacific? J Mar Res 41:327-347

Weaver AJ (1993) The oceans and global warming. Nature 364:192-193

Weaver AJ, Sarachik ES (1991) The role of mixed boundary conditions in numerical models of the ocean's climate. J Phys Oceanogr 21:1470-1493

Weaver AJ, Marotzke J, Cummins PF, Sarachik ES (1993) Stability and variability of the thermohaline circulation. J Phys Oceanogr 23:39-60

Zhang S, Greatbatch RG, Lin CA (1993) A reexamination of the polar halocline catastrophe and implications for coupled ocean-atmosphere modeling. J Phys Oceanogr 23:287-299 